\title{
Feasibility Study for Production of Zeolite A based on Kaolin
}

\author{
Agustina A.Y. Simanjuntak ${ }^{1}$, and E. Kusrini ${ }^{1 *}$ \\ ${ }^{1}$ Department of Chemical Engineering, Faculty of Engineering, Universitas Indonesia, Depok, 16424, Indonesia
}

\begin{abstract}
In industry, kaolin is widely employed as an additive to paper, rubber and ceramics, among other uses, and can be synthesized into zeolite. Zeolites have been hydrothermally synthesized using alumina and silica based on deposits (kaolin) sampled from region in BangkaBelitung. The synthesis of Zeolite A based on kaolin through several process stages such as drying, grinding and sieving prior to the hydrothermal process. It is then calcined into metakaolin, followed by the addition of $\mathrm{NaOH}$ solution, heating, filtration and washing to obtain the synthesis. This study examines how assessment models can be built and used for financial, technical, and marketing feasibility analysis of synthesized Zeolite A from kaolin. A new optimization method used to estimate financing requirements of investment products is presented, as well as a new method to predict the optimal year to sell the product. The conclusion is that Net Present Value with a positive value, Pay Back Period, Internal Rate of Return $30.78 \%$ higher than the interest rate set at $12 \%$, and marketing aspects show that the process is feasible.
\end{abstract}

\section{Introduction}

Geologically, Indonesia's territory has the world's largest kaolin deposits; it has many kaolin producing regions, which not only meet domestic demand, but also make it possible to export the product of kaolin. BangkaBelitung is a newly developed region, with high natural resource potential, such as tin. Beside tin, BangkaBelitung is also a producer of kaolin, with 2,250 ha of land yielding the potential for 4,095,000 tons of kaolin.

In industry, kaolin is widely used as an additive to paper, paint, ink, rubber, ceramics and plastics. In addition, it can be synthesized into zeolite. Zeolite is an alumina silica crystal that has a three-dimensional frame structure. It is formed by tetrahedral silica $\left(\mathrm{SiO}_{4}{ }^{4-}\right)$ and alumina $\left(\mathrm{AlO}_{4}{ }^{5-}\right)$ with cavities filled with metal ions, usually alkaline or alkaline earth, and water molecules. With the chemical formula $\mathrm{Al}_{2} \mathrm{O}_{3} \cdot 2 \mathrm{SiO}_{2} \cdot 2 \mathrm{H}_{2} \mathrm{O}$ kaolin is a rock composed of clay minerals with low iron content [1]. It is generally white and most of the components contained in it are silica and alumina. The high silica and alumina content in kaolin can be used as the basic materials for the synthesis of zeolite. Based on this, this study will test the utilization of kaolin as the basic material in the synthesis of zeolite A.

The type of zeolite produced depends on the initial composition and conversion method. The most commonly used method is a hydrothermal alkali treatment which heats mixture with an alkaline solution $(\mathrm{KOH}, \mathrm{NAOH}$, etc). Direct hydrothermal zeolite production has a shorter stage than the smelting or extraction method, although the purify level is still much lower when compared to the two methods [2].
Ayele et al. successfully optimized the synthesis parameters of zeolite A from Ethiopian kaolin. All the above optimized conditions resulted in the synthesis of zeolite A with high crystallinity of about $90 \%$, cubic crystal of zeolite $\mathrm{A}$ with rounded edge, $\mathrm{Si} / \mathrm{Al}=1$, high thermal stability and cation exchange capacity of 295 $\mathrm{CaCO}_{3} / \mathrm{g}$ of anhydrous zeolites. These results show that the work done here produced zeolite A suitable for the use in detergents formulation [3].

The feasibility study is procedure to predict outcome of an assessment of a planned scheme along with posible gain [4]. These studies allow proper evaluating any production and also on the essential requirement to commence the project. A feasibility studies are important and essential to evolutes the any proposed project is feasible or not. There are two main motivations regarding this area location assessment of the desire project and cost expectation [5]. This study also helps to see viability of the particular idea which gives the fruitful deliverable from the project within optimal cost, time, resources, and also justifying the factors like technical and economical of raw material availability from kaolin which is efficient and has a good sales value both domestically and overseas. In general, zeolite both natural zeolite and synthetic zeolite have high economic value. Like natural zeolites, synthetic zeolites such as zeolite A can also be optimized for use [6].

\section{Materials and Areas of Project Feasibility}

\subsection{Materials}

Corresponding author: eny.k@ui.ac.id 
The raw material used to synthesis the zeolite was kaolin, since its major components are silica and alumina, consisting of $60.49 \%-83.02 \% \quad \mathrm{SiO}_{2}$ and $10.63 \%-24.19 \%$ alumina $\mathrm{Al}_{2} \mathrm{O}_{3}$ thus allowing the kaolin to be synthesized into zeolite. The kaolin used came from the Bangka-Belitung region with a high percentage chemical characterization $\left(\mathrm{SiO}_{2}\right.$ and $\left.\mathrm{Al}_{2} \mathrm{O}_{3}\right)$, as required in the raw material for the synthesis of zeolite A. Bangka Belitung kaolin quality is almost the same as that from Ranong and China, but Ahoko kaolin contains a higher level of $\mathrm{SiO}_{2}$ [7].

Table 1. Chemical characterization of kaolin from BangkaBelitung and from other countries

\begin{tabular}{|c|c|c|c|c|c|}
\hline \multirow[b]{2}{*}{$\begin{array}{c}\text { Chemical } \\
\text { Characterization }\end{array}$} & \multicolumn{5}{|c|}{ \% Weight } \\
\hline & $\begin{array}{l}\text { Bangka- } \\
\text { Belitung }\end{array}$ & $\begin{array}{l}\text { Ahoko, } \\
\text { Nigeria }\end{array}$ & $\begin{array}{l}\text { Ranong, } \\
\text { Thailand }\end{array}$ & China & Georgia \\
\hline $\mathrm{SiO}_{2}$ & 49.86 & 72.46 & 45.63 & 44.21 & 45.30 \\
\hline $\mathbf{A l}_{2} \mathbf{O}_{3}$ & 30.51 & 18.96 & 35.75 & 37.75 & 38.38 \\
\hline $\mathrm{Fe}_{2} \mathrm{O}_{3}$ & 0.69 & 1.05 & 0.77 & 0.78 & 0.30 \\
\hline $\mathrm{TiO}_{2}$ & 0.29 & - & 0.04 & - & 1.44 \\
\hline $\mathrm{CaO}$ & 1.49 & - & 0.02 & 0.45 & 0.05 \\
\hline MgO & 1.07 & 0.13 & 0.04 & 0.08 & 0.25 \\
\hline $\mathrm{Na}_{2} \mathrm{O}$ & 0.45 & 0.02 & - & 0.07 & 0.27 \\
\hline $\mathrm{K}_{2} \mathrm{O}$ & 0.59 & 0.43 & 0.99 & 0.46 & 0.44 \\
\hline $\begin{array}{l}\text { Loss on } \\
\text { ignition }\end{array}$ & 15.05 & 6.17 & 13.38 & 17.25 & 13.97 \\
\hline
\end{tabular}

[8]

\subsection{Areas of Project Feasibility}

In this study discuss different area of the project feasibility which may be consider during the assessment of any project. The methodical study may also provide the exact respond earlier. Feasibility evaluation mainly classify in four types or categories.

\subsubsection{Technical Feasibility}

The technical study discusses how the products are to be produced, when these products are to be produced, how much will it cost to produce the products, where to produce the products and what technology to be used.

\subsubsection{Economic Feasibility}

Economic feasibility study related with price, and all kind of expenditure related with the scheme before the project start. This study also improves project reliability [9]. It is also helpful for the decision-makers to decide the planned scheme processed latter or now, depending financial condition of the organization. This evaluation process also studies the price benefits of the proposed scheme.

\subsubsection{Operational Feasibility}

Operational feasibility may employ the responsibility to examine and also decide whether the proposed methods fulfill all kind of business requirements [10]. It actions forecast all possible schemes to recognized and resolves troubles. This studies may also examine and verify how the project planed guarantee the method development is feasible or not.

\subsubsection{Marketing Feasibility}

A market feasibility study determines the depth and condition of a particular real estate market and its ability to support a particular development. Things to include in a market feasibility study include; current market analysis, competition, anticipated future market potential, and potential buyers and sources of revenues [11].

\subsection{Financial Data Collection}

The first data were the target prices of the raw materials. Based on the target selling price of 5.4 million from market, the market margin is equal to $73 \%$, the total labor cost is equal to IDR 900,000, and the minimum level of company profit is equal to $15 \%$, so the price strategy for the raw material targets a maximum of IDR $2,500,000 /$ ton. Other data obtained included the cost of raw materials and the cost of the company. Kaolin raw material and support costs $=$ IDR 2,400,000/ton, and $\mathrm{NaOH}=$ IDR 100.000/litre. Therefore, the total cost of the raw materials amounted to IDR 2,500,000/ton. The company margins were IDR $510,000,15 \%$ of the total cost of the raw materials, and labor costs IDR 3.400.000. Calculation of the machine costs in IDR included three rotary drum dryers at IDR 600 millions, three pieces of grinder at 800 millions, three vertical crystallizers at 950 millions, three heat exchangers at 1100 millions, three create disc filter $=900$ million in addition to machine import tax and shipping costs of 2319,76 million. The cost of developing new products was 435 million, so the total investment required was IDR 15,804,760,000. Engine life is 10 years, while the bank interest rate was assumed to be $12 \%$, as applicable at the times.

\section{Result and Discussion}

Synthesis of zeolite A was developed to overcome the disadvantages of natural zeolite due to its varying mineral composition and uniform pore size. Development of synthetic zeolites can be made by adjusting the pores to allow more specific utilization. This is also supported by the high potential reserves of kaolin in the Bangka-Belitung region, which will support the effectiveness of the production of kaolinbased zeolite A.

Essentially, the synthesis of zeolite A has high economic value, and it can be utilized and processed for other functions, such as a concentrate for alcohol, olefin dryers, solid natural gas materials or air $\mathrm{CO}_{2}$ cleaners. The functionality of zeolite for $\mathrm{CO}_{2}$ gas adsorbents has been widely developed, including its synthesis to modify its structure and to increase the surface area and pores.

In successful project feasibility study is a critical factor. Therefore, the basic features in any feasibility 
study must be ensuring are working with accurate information, exact statement, and the latest financial records [12]. The main objective of feasibility study is to evaluate three types of feasibility; technical, operational, and economic feasibility.

\subsection{Technical Feasibility}

The technical feasibility study should most essentially support the financial information of an organization. The technical analysis concern projects inputs (supplies) and outputs (production) of real goods and services. From the technical point of view, the raw material inventory amounted to IDR 2,500,000/ton, according to raw material price target of IDR 2,500,000/ton which also supported include the quality of machinery and equipment's. Synthesis of zeolite A from kaolin is using thermal activation of chemically inert crystalline kaolin to obtain a more reactive and amorphous phase, metakaolin. The resultant zeolite type and relative abundance depend on the hydrothermal conditions.

\subsection{Economic Feasibility}

\subsubsection{Pay Back Period Analysis}

Calculation by the Pay Back Period Analysis method is shown in table 2 .

Table 2. Payback period analysis (PP)

\begin{tabular}{ccc}
\hline Month & Net Cash Flow (IDR) & $\begin{array}{c}\text { Cumulative Cash } \\
\text { Flow (IDR) }\end{array}$ \\
\hline $\mathbf{0}$ & -15804760000 & -15804760000 \\
\hline $\mathbf{1}$ & 1020000000 & -14784760000 \\
\hline $\mathbf{3}$ & 1020000000 & -13764760000 \\
\hline $\mathbf{4}$ & 1020000000 & -12744760000 \\
\hline $\mathbf{5}$ & 1020000000 & -11724760000 \\
\hline $\mathbf{6}$ & 1020000000 & -10704760000 \\
\hline $\mathbf{7}$ & 1020000000 & -9684760000 \\
\hline $\mathbf{8}$ & 1020000000 & -866476000 \\
\hline $\mathbf{9}$ & 1020000000 & -7644760000 \\
\hline $\mathbf{1 0}$ & 1020000000 & -6624760000 \\
\hline $\mathbf{1 1}$ & 1020000000 & -5604760000 \\
\hline $\mathbf{1 2}$ & 1020000000 & -4584760000 \\
\hline $\mathbf{1 3}$ & 1020000000 & -3564760000 \\
\hline $\mathbf{1 4}$ & 1020000000 & -2544760000 \\
\hline $\mathbf{1 5}$ & 1020000000 & -1524760000 \\
\hline $\mathbf{1 6}$ & 1020000000 & -504760000 \\
\hline & 1020000000 & 515240000 \\
\hline$P P=15+(16-15) x$ & \\
$P P=15.505$ & months
\end{tabular}

\subsubsection{Internal Rate of Return (IRR)}

Calculation by the Internal Rate of Return method is shown in table 3 .

Table 3. Internal rate of return (IRR)

\begin{tabular}{llllll}
\multicolumn{5}{c}{ Table 3. Internal rate of return (IRR) } \\
\hline Month & $\begin{array}{l}\text { Net Cash Flow } \\
\text { (IDR) }\end{array}$ & $\mathbf{( r )} \mathbf{2 , 5} \%$ & Net Value & $\mathbf{( r )}$ & Net Value \\
& & & $\mathbf{2 , 7 5 \%}$ & \\
\hline $\mathbf{0}$ & -15804760 & 1.0000 & -15804760 & 1 & -15804760 \\
\hline $\mathbf{1}$ & 1020000 & 0.9756 & 995112 & 0.9732 & 992664 \\
\hline $\mathbf{2}$ & 1020000 & 0.9518 & 970836 & 0.9472 & 966144 \\
\hline
\end{tabular}

\begin{tabular}{llllll}
\hline $\mathbf{3}$ & 1020000 & 0.9286 & 947172 & 0.9218 & 940236 \\
\hline $\mathbf{4}$ & 1020000 & 0.9060 & 924120 & 0.8972 & 915144 \\
\hline $\mathbf{5}$ & 1020000 & 0.8839 & 901578 & 0.8372 & 853944 \\
\hline $\mathbf{6}$ & 1020000 & 0.8623 & 879546 & 0.8498 & 866796 \\
\hline $\mathbf{7}$ & 1020000 & 0.8413 & 858126 & 0.8270 & 843540 \\
\hline $\mathbf{8}$ & 1020000 & 0.8207 & 837114 & 0.8049 & 820998 \\
\hline $\mathbf{9}$ & 1020000 & 0.8007 & 816714 & 0.7834 & 799068 \\
\hline $\mathbf{1 0}$ & 1020000 & 0.7812 & 796824 & 0.7624 & 777648 \\
\hline $\mathbf{1 1}$ & 1020000 & 0.7621 & 777342 & 0.7420 & 756840 \\
\hline $\mathbf{1 2}$ & 1020000 & 0.7436 & 758472 & 0.7221 & 736542 \\
\hline $\mathbf{1 3}$ & 1020000 & 0.7254 & 739908 & 0.7028 & 716856 \\
\hline $\mathbf{1 4}$ & 1020000 & 0.7077 & 721854 & 0.6840 & 697680 \\
\hline $\mathbf{1 5}$ & 1020000 & 0.6905 & 704310 & 0.6657 & 679014 \\
\hline $\mathbf{1 6}$ & 1020000 & 0.6736 & 687072 & 0.6479 & 660858 \\
\hline $\mathbf{1 7}$ & 1020000 & 0.6572 & 670344 & 0.6305 & 643110 \\
\hline $\mathbf{1 8}$ & 1020000 & 0.6412 & 654024 & 0.6137 & 625974 \\
\hline $\mathbf{1 9}$ & 1020000 & 0.6255 & 638010 & 0.5972 & 609144 \\
\hline $\mathbf{2 0}$ & 1020000 & 0.6103 & 622506 & 0.5813 & 592926 \\
\hline Total & & & 96224 & & -272914 \\
\hline & & & & &
\end{tabular}

$$
\begin{aligned}
& I R R=0,025+(0,0275-0,025) x \frac{96.224}{96.224-(-272.914)} \\
& \begin{aligned}
I R R \text { in a year } & =2,56 \% \times 12 \\
& =\mathbf{3 0 . 7 8} \%
\end{aligned}
\end{aligned}
$$

\subsubsection{Net Present Value (NPV)}

Calculation by the Net Present Value method is shown in table 4.

Table 4. Net present value (NPV)

\begin{tabular}{llll}
\hline Month & Net Cash Flow & $\begin{array}{c}\text { Discount Factor } \\
(\mathbf{1})\end{array}$ & Net Present Value \\
\hline $\mathbf{0}$ & -15804760 & 1.0000 & -15804760 \\
\hline $\mathbf{1}$ & 1020000000 & 0.9901 & 1009902000 \\
\hline $\mathbf{2}$ & 1020000000 & 0.9803 & 999906000 \\
\hline $\mathbf{3}$ & 1020000000 & 0.9706 & 990012000 \\
\hline $\mathbf{4}$ & 1020000000 & 0.9610 & 980220000 \\
\hline $\mathbf{5}$ & 1020000000 & 0.9515 & 970530000 \\
\hline $\mathbf{6}$ & 1020000000 & 0.9420 & 960840000 \\
\hline $\mathbf{7}$ & 1020000000 & 0.9327 & 951354000 \\
\hline $\mathbf{8}$ & 1020000000 & 0.9235 & 941970000 \\
\hline $\mathbf{9}$ & 1020000000 & 0.9143 & 932586000 \\
\hline $\mathbf{1 0}$ & 1020000000 & 0.9053 & 923406000 \\
\hline $\mathbf{1 1}$ & 1020000000 & 0.8963 & 914226000 \\
\hline $\mathbf{1 2}$ & 1020000000 & 0.8874 & 905148000 \\
\hline $\mathbf{1 3}$ & 1020000000 & 0.8787 & 896274000 \\
\hline $\mathbf{1 4}$ & 1020000000 & 0.8700 & 887400000 \\
\hline $\mathbf{1 5}$ & 1020000000 & 0.8613 & 878526000 \\
\hline $\mathbf{1 6}$ & 1020000000 & 0.8528 & 869856000 \\
\hline $\mathbf{1 7}$ & 1020000000 & 0.8444 & 861288000 \\
\hline $\mathbf{N e t}$ Present Value & & 68684000 \\
\hline
\end{tabular}

\subsection{Operational Feasibility}

\subsubsection{Forecasting of needs with constant forecasting}

Calculation of assumptions with the constant forecasting method is shown in table 5 .

Table 5. Constant Forecasting of Kaolin Needs

\begin{tabular}{cccccc}
\multicolumn{5}{c}{ Table 5. Constant Forecasting of Kaolin Needs } \\
Year & T & d & d' $^{\prime}$ & d-d' & (d-d')2 \\
$\mathbf{2 0 1 8}$ & 1 & 82000 & 95275 & -13275 & 176225625
\end{tabular}




\begin{tabular}{cccccc}
\hline $\mathbf{2 0 1 9}$ & 2 & 90500 & 95275 & -4775 & 22800625 \\
\hline $\mathbf{2 0 2 0}$ & 3 & 110200 & 95275 & 14925 & 222755625 \\
\hline $\mathbf{2 0 2 1}$ & 4 & 98400 & 95275 & 3125 & 9765625 \\
\hline Quantity & $\mathbf{1 0}$ & $\mathbf{3 8 1 1 0 0}$ & & $(-)$ & $\mathbf{4 3 1 5 4 7 5 0 0}$ \\
\hline
\end{tabular}

$$
\begin{gathered}
d^{\prime}=\frac{\sum d}{n} \\
d^{\prime}=\frac{381100}{4}=95.275
\end{gathered}
$$

From the calculation of forecasting requirements above a Standard Error of Estimate (SEE) was obtained, as follows:

$$
\begin{aligned}
& S E E=\sqrt{\frac{\sum\left(d-d^{\prime}\right)^{2}}{n-1}} \\
& S E E=\sqrt{\frac{431.547 .500}{3}} \\
& S E E=11.994
\end{aligned}
$$

\subsubsection{Forecasting of needs with linear forecasting}

Calculation of assumptions with the linear forecasting method is shown in table 6 .

Table 6. Linear forecasting of kaolin needs

\begin{tabular}{cccccccc}
\multicolumn{8}{c}{ Table 6. Linear forecasting of kaolin needs } \\
\hline Year & $\mathbf{T}$ & $\mathbf{d}$ & $\mathbf{d t}$ & $\mathbf{t 2}$ & $\mathbf{d}^{\prime}$ & $\mathbf{d - d}$ & $\mathbf{d d - d}^{\prime} \mathbf{2}$ \\
$\mathbf{2 0 1 8}$ & 1 & 82000 & 82000 & 1 & 34025 & 47975 & 2301619815 \\
& 2 & 90500 & 181000 & 4 & 35458 & 55042 & 3029665798 \\
\hline $\mathbf{2 0 1 9}$ & 2 & & & & & & \\
$\mathbf{2 0 2 0}$ & 3 & 110200 & 330600 & 9 & 36890 & 73310 & 5374297452 \\
\hline $\mathbf{2 0 2 1}$ & 4 & 98400 & 393600 & 16 & 38323 & 60077 & 3609221898 \\
\hline Quantity & 10 & 381100 & 987200 & 30 & 144696 & 236404 & 14314804963 \\
\hline
\end{tabular}

From the above calculation, the values of $a$ and $b$ can be obtained, as follows:

$$
\begin{aligned}
a & =\frac{\sum d \sum t^{2}-\sum t \sum d t}{n \sum t^{2}-\left(\sum t\right)^{2}} \\
d^{\prime} & =78.050+6.890(t)
\end{aligned}
$$

From the calculation of forecasting requirements above, a Standard Error of Estimate (SEE) was obtained, as follows:

$$
\begin{aligned}
S E E & =\sqrt{\frac{\sum\left(d-d^{\prime}\right)^{2}}{n-2}} \\
S E E & =\sqrt{\frac{14.314 .804 .963}{2}} \\
S E E & =\mathbf{8 4 . 6 0 1}
\end{aligned}
$$

\subsubsection{Forecasting of needs with cycle forecasting}

Calculation of assumptions with the cycle forecasting method is shown in table 7 .

Table 7. Cycle forecasting of kaolin needs

\begin{tabular}{lccccccccc}
\multicolumn{10}{c}{ Table 7. Cycle forecasting of kaolin needs } \\
\hline Year & $\mathbf{t}$ & $\mathbf{D}$ & $\mathbf{c o s}$ & $\mathbf{d c o s}$ & $\mathbf{s i n}$ & $\mathbf{d s i n}$ & $\mathbf{d}$ & $\mathbf{d - d}$ & (d-d')2 \\
& & & $\mathbf{9 0 t}$ & $\mathbf{9 0 t}$ & $\mathbf{9 0 t}$ & $\mathbf{9 0 t}$ & & & \\
\hline $\mathbf{2 0 1 8}$ & 1 & 82000 & 0 & 0 & 1 & 8200 & 98991 & -16991 & 288701953 \\
\hline
\end{tabular}

\begin{tabular}{cccccccccc}
\hline $\mathbf{2 0 1 9}$ & 2 & 90500 & -1 & -90500 & 0 & 0 & 102707 & -12207 & 149022160 \\
\hline $\mathbf{2 0 2 0}$ & 3 & 110200 & 0 & 0 & -1 & -110200 & 106424 & 3776 & 14260480 \\
\hline $\mathbf{2 0 2 1}$ & 4 & 98400 & 1 & 98400 & 0 & 0 & 110140 & - & 137825875 \\
\hline Qty & 10 & 381100 & 0 & 7900 & 0 & -28200 & 418262 & -37162 & 589810468 \\
\hline
\end{tabular}

$$
\begin{gathered}
d^{\prime}=a+u \cdot \cos \frac{2 \pi}{N} \cdot t+v \cdot \sin \frac{2 \pi}{N} \cdot t \\
d^{\prime}=95.275+3.950 \cdot \cos 90 \cdot t-14.100 \cdot \sin 90 . t
\end{gathered}
$$

From the calculation of forecasting requirements above, a Standard Error of Estimate (SEE) was obtained, as follows:

$$
\begin{gathered}
S E E=\sqrt{\frac{\sum\left(d-d^{\prime}\right)^{2}}{n-2}} \\
S E E=\sqrt{\frac{589.810 .468}{1}} \\
S E E=24.286
\end{gathered}
$$

Based on the calculation of the Standard Error of Estimate (SEE) value of the three forecasting methods employed, the constant forecasting method was chosen to forecast kaolin needs.

\subsection{Marketing Feasibility}

Market analysis is an extremely important step after completing identifying the investment opportunities, and the initial feasibility study. From the results of the needs forecasting of kaolin-based zeolite A synthesis of 7,940 tons per month, and of a product sales plan of 2,000 tons per month, this means that the product will capture $25 \%$ of the existing market share (Constant SEE=11994). This is feasible, because customer behavior with regard to the synthesis of zeolite A-based commercial kaolin is not loyal towards a specific brand. As long as quality, price and distribution can be met, it will be well received by the market. In terms of marketing, the cost of raw materials that matches the target marketing will make the selling price of the kaolin products competitive.

The quality and accuracy of the collected data and information on the variables of market analysis of the proposed business leads to the safety and accuracy of decision making on either proceed further on establishing the business. The demand analysis refers to the organized processes aiming at exploration of a certain variable behavior (demand) in future, based on a systematic study of the existing historical data. Demand, in itself, is an economical term indicating the volume or quantity of the commodities and/or services demanded within a certain period, at a certain price level, and from a certain market. The demand will be analyzed both in the past and future through the use of the mathematical methods so as to predict the actual demand on the commodity or service in future.

Price is one of the important variables in the market analysis process, because price affect the demand on the products and the way they are introduced into the markets. Price also have their strong influence upon the production processes, such as methods or means of production, as well as other effects of prices. From 
consumer's point of view, price expresses the cost of getting the product. Competition plays an important role in market analysis, and is deemed the party that offers similiar or typical products of the proposed investment business of both the same curent and anticipated consumer segments [13].

\section{Conclusion}

Basically it is a predictable project that demonstrate conclusion of the assessment, examine, and evaluation of a designed method and terminate if this method is accurately feasible, profitable, and productive. Based on the analysis and discussion it can be concluded from the results of the product feasibility study that the market and marketing aspects are feasible. The financial aspects are also considered feasible, when reviewed from the financial analysis of PP 15,505 months lower than the economic value of machine 10 years, IRR $30.78 \%$ which is higher than the interest set $12 \%$ and the positive value of NPV IDR $68,857,400$.

The authors wish to thank the Universitas Indonesia. This article's publication is partially supported by the United States Agency for International Development (USAID) through the Sustainable Higher Education Research Alliance (SHERA) Program for Universitas Indonesia's Scientific Modeling, Application, Research and Training for City-centered Innovation and Technology Project, Grant No. AID-497-A1600004, Sub Grant No. IIE-00000078-UI-1.

\section{References}

1. Gougazeh, M., \& Buhl, J.-Ch. (2014). Synthesis and characterization of zeolite a by hydrothermal transformation of Natural Jordanian Kaolin. Journal of the Association of Arab Universities for Basic and Applied Science, 15, 35-42.

2. Syukuri Nikmah, R.A., Nurul Widiastuti, \& Hamzah Fansuri. (2008). The effect of time and comparison of $\mathrm{Si} / \mathrm{Al}$ to the formation of Zeolite A from free carbon basic ash from PLTU PT IPMOMI with hydrothermal methods. Journal of Indonesia Zeolites, Vol. 7 No. 1.

3. Ayele, Lijalem, Joaquin Perez-Pariente, Yonas Chebude, Isabel Diaz. (2015). Synthesis of Zeolite A from Ethiopian Kaolin. Microporous and Mesoporous Materials 215, 29-36.

4. Krieger, T., Martig, D.S., van den Brink, E., \& Berger, T. (2016). Working on self-compassion online: A proof of concept and feasibility study. Internet Interventions, 6, 64-70.

5. Liaquat, A. M., Kalam, M.A., Masjuki, H. H., \& Jayed, M. H. (2010). Potential emissions reduction in road transport sector using biofuel in developing countries. Atmospheric Environment, 44 (32), 38693877.

6. Saputra, Rodhie. (2006). Utilization of synthetic zeolites as an alternative of industrial waste processing.
7. Ibrahim, H.S., Jamil, T.S., \& Hegazy, E.Z. (2010). Application of zeolite prepared from Egyptian Kaolin for the removal of heavy metals: II (isoterm models. Journal of Hazardous Materials, Vol. 182 (1-3), pp 842-847.

8. Goldman, M., Fraenkel, D., \& Gideon, L. (2003). A zeolite/polymer membrane for separation of ethanolwater azeotrope. Journal of Applied Polymer Science, 37 (7), pp 1791-1800.

9. Schwender, J.D., Holly, L.T., Rouben, D.P., \& Foley, K. T. (2005). Minimally invasive transforaminal lumbar interbody fusion (TLIF) : technical feasibility and initial results. Clinical Spine Surgery, 18, S1-S6.

10. Pollock, J., Ho, S. V., \& Farid, S. S. (2013). Fedbatch and perfusion culture processes:Economic, environmental, and operational feasibility under uncertainty. Biotechnology and bioengineering, 110 (1), 206-219.

11. Roy, A., \& Mukherjee, K. (2017). Entrepreneurial Education in India. International Journal of Advanced Engineering and Management, 2(1), 1520.

12. Adams, J., Khan, H. T., Raeside, R., \& White, D. I. (2007). Research methods for graduate business and social science students. SAGE publications India.

13. Yousuf, Tawfiq Abdul Rahim. (2002). Management of small business. Amman: Dar Safa'a for publishing and distribution. 